\title{
THE EFFECT OF THE TYPE OF INHALED ANTI-ASTHMATIC THERAPY ON THE PROPERTIES OF SALIVA IN CHILDREN - A PHANTOM STUDY
}

\author{
Magdalena Świątkowska-Bury' ${ }^{1}$ Anna Zawadzka-Krajewska², Marek Kulus², Dorota Olczak-Kowalczyk' \\ 'Department of Paediatric Dentistry, Medical University of Warsaw, Poland \\ ${ }^{2}$ Department of Child Pneumonology and Allergology, Warsaw Medical University, Warsaw, Poland
}

\begin{abstract}
INTRODUCTION: Asthma is the most common chronic childhood disease, mainly treated with inhaled steroid anti-inflammatory drugs (ICSs) and inhaled bronchodilators. Unfortunately, current literature emphasizes their negative effect on the condition of soft tissues of the oral cavity and hard dental tissues.

ОвјестіVEs: The aim of the study was to assess the effect of types of inhaled anti-asthmatic drugs on the properties of saliva in children.

MATERIAL AND METHODs: Study group included 114 asthmatics and 94 healthy patients between the age of 3 and 17. Information about the age of onset, severity of asthma, use of anti-asthmatic medications, duration of the therapy, method of drugs' administration, and number of their application were recorded. The severity of asthma was assessed by a pediatrician. Saliva was collected for resting $\mathrm{pH}$, buffering capacity, hydration, saliva quantity, and viscosity measurements using saliva-check buffer kit (GC). Student's $t$-test, $\chi^{2}$ test, Mann-Whitney $U$ test, and Spearman's correlation coefficient were used, with a significance level of $p<0.05$.

RESULTS: Asthmatics appeared to be characterized by significantly lower average values of saliva quantity $(p=0.0064)$, buffering capacity $(p=0.0002)$, and viscosity $(p=0.0094)$ than controls. Spearman's rank correlation revealed a negative correlation between steroid dose, therapy duration, and the use of dry powder inhalers (DPIs) on saliva quantity. Moreover, combination therapy with $\beta_{2}$-agonists and DPIs reduces hydration of lip mucosa. Finally, the use of DPIs increases the viscosity of saliva.

Conclusions: The study shows that inhaled anti-asthmatic medications have a considerable effect on salivary properties.
\end{abstract}

KEY WORDS: children, asthma, anti-asthmatic therapy, saliva properties.

J Stoma 2021; 74, 1: 22-27

DOI: https://doi.org/10.5114/jos.2021.104694

\section{INTRODUCTION}

Asthma, the most common chronic childhood disease, belongs to the group of allergic diseases. It is estimated that asthma affects around 339 million people worldwide; this number is increasing due to global urba- nization [1-3]. Asthma is characterized by chronic inflammation of the airways, causing contraction of smooth muscle and increased mucus secretion in the bronchial tree. This results in characteristic symptoms, such as sudden attacks of breathlessness, tightness of the chest, coughing, and wheezing breath. Usually, an asth-

\section{JOURNAL OF} STOMATOLOGY CZASOPISMO STOMATOLOGICZNE

AdDress For Correspondence: Prof. Dorota Olczak-Kowalczyk, Department of Pediatric Dentistry, Warsaw Medical University, 6 Binieckiego St., 02-097 Warsaw, Poland, e-mail: do-k@tlen.pl 
matic attack is sudden and acute, posing a direct threat to patient's life [4]. The treatment of asthma is based on avoiding allergic factors causing exacerbation of the disease, chronic use of long- and short-acting inhaled bronchodilators ( $\beta_{2}$-agonists, LABA/SABA), and inhaled steroid anti-inflammatory drugs (inhaled corticosteroids [ICSs]) [4]. Current studies emphasize the adverse and negative local impact of these medications on the condition of soft tissues of the oral cavity and hard dental tissues [5-9]. The most frequently observed problems in the oral cavity include predispositions to the development of tooth decay and tooth wear, oral candidiasis, and the appearance of mucosal erosions and ulcers. It is also believed that inhaled anti-asthmatic drugs may cause xerostomia. Several authors have observed a negative effect of the therapy on the properties of saliva, such as the buffering capacity, and $\mathrm{pH}$ flow rate [10-12]. However, other studies have shown no such correlation, which makes the issue still an arguable topic [13-15].

\section{OBJECTIVES}

The aim of the study was to assess the effect of types of inhaled anti-asthmatic drugs on salivary properties in children between 3 and 17 years old.

\section{MATERIAL AND METHODS}

The study group included patients diagnosed with asthma who had been treated with steroid inhaled therapy (ICSs) or combined therapy with $\beta_{2}$-agonists at the Department of Child Pneumonology and Allergology of Medical University of Warsaw. Patients who qualified for the control group were generally healthy, took no medications, and were regularly treated at the Department of Pediatric Dentistry of Medical University of Warsaw. The inclusion criteria for both groups were as follows: age 3-17 years old, cooperation of the patient (permitting for clinical examination), and written consent of the parent/legal guardian and/or the patient to participate in the study. The consent of the Bioethics Committee (No. KB/6/2017) was obtained. The study was carried out during 2017 and 2018. Information about patients' general health status and medications used were based on analysis of patients' medical history and interviews with parents or legal guardians. Information regarding the age of onset, severity of asthma, use of anti-asthmatic medications, and duration of the therapy, method of drugs' administration, and number of their application were recorded. The severity of asthma was assessed by a pediatrician according to GINA classification [16]. Mild asthma was identified in patients requiring low doses of ICSs or as-needed low doses of ICS-formoterol; moderate asthma in cases with low doses of ICS-LABA; and severe asthma in patients with medium to high doses of ICS-LABA.
Salivary properties were tested in each patient using saliva-check buffer kit (GC). Saliva was collected during morning hours, at least 2 hours after a meal. Patients were requested to refrain from brushing their teeth and using antibacterial mouthwashes prior to the examination. Resting $\mathrm{pH}$ value, buffering capacity, and saliva composition were assessed using the saliva-check buffer kit (GC). Hydration (time elapsed following the appearance of saliva droplets on the lower lip mucosa, or 60 seconds) and viscosity ( 1 - watery, clear saliva; 2 - frothy, bubbly saliva; 3 - sticky, frothy saliva residues) were assessed visually. The patient, while chewing paraffin for five minutes in an upright position, was asked to collect saliva in a calibrated sterile tube. $\mathrm{pH}$ values of resting saliva were considered normal within a range of 6.8-7.8, moderately acidic within a range of 6.0-6.6, and acidic within a range of 5.0-5.8. Secretion of stimulated saliva in an amount exceeding $5.0 \mathrm{ml}$, obtained within 5 minutes, was identified as normal; within a range of 3.5-5.0 ml/5 min as low, and in amounts below $3.5 \mathrm{ml} / 5 \mathrm{~min}$ as very low. The buffering capacity of stimulated saliva was estimated according to a colorimetric test strip after $5 \mathrm{~min}$ of reaction time (green -4 points, green/blue -3 points, blue -2 points, blue/red - 1 point, red - 0) as normal (10-12 points), as low (6-9 points), or as very low (0-5 points).

\section{STATISTICAL ANALYSIS}

The results were entered into a database and subjected to statistical analysis using Statistica v.13.3 (Student's $t$-test, $\chi^{2}$ test, Mann-Whitney $U$ test, Spearman's correlation coefficient). The significance level was set at $<0.05$.

\section{RESULTS}

Of 222 children invited for dental examination, 14 were excluded due to a lack of cooperation (8 children), consumption of sweet snacks or drinks prior to examination ( 2 children), or a lack of a complete medical history or information in the questionnaire (4 children). Ultimately, 208 children were included in the study: $86(41.3 \%)$ girls and 122 (58.7\%) boys. Numbers of children examined in the study and from control group are presented in Table 1.

TABLE 1. Numbers and percentages of children included in the examination

\begin{tabular}{|l|c|c|c|}
\hline Parameter & $\begin{array}{c}\text { Study } \\
\text { group }\end{array}$ & $\begin{array}{c}\text { Control } \\
\text { group }\end{array}$ & All \\
\hline Number of patients, $n(\%)$ & $114(100)$ & $94(100)$ & $208(100)$ \\
\hline \begin{tabular}{l} 
Gender, $n(\%)$ \\
\hline Male
\end{tabular} & $71(62.3)$ & $51(54.3)$ & $122(58.7)$ \\
\hline Female & $43(37.7)$ & $43(45.7)$ & $86(41.3)$ \\
\hline Average age \pm SD & $8.02 \pm 4.95$ & $8.35 \pm 3.69$ & $8.19 \pm 3.83$ \\
\hline
\end{tabular}


TABLE 2. Age at diagnosis and type and duration of antiasthmatic therapy

\begin{tabular}{|c|c|}
\hline \multicolumn{2}{|l|}{ Parameter } \\
\hline \multicolumn{2}{|l|}{ Onset of asthma (months) } \\
\hline Interval (M) & $0.5-154$ \\
\hline Average $(M \pm S D)$ & $39 \pm 26.83$ \\
\hline \multicolumn{2}{|l|}{ Duration of therapy } \\
\hline Interval (M) & $2-183$ \\
\hline Average $(M \pm S D)$ & $58 \pm 42.83$ \\
\hline \multicolumn{2}{|l|}{ Inhaled corticosteroid drug used (ICS), $n(\%)$} \\
\hline Fluticasone propionate (FP) & $92(80.7)$ \\
\hline Budesonide (BUD) & $7(6.1)$ \\
\hline Combined therapy (ICSs + long-acting $\beta_{2}$-agonists), $n$ (\%) & $15(13.2)$ \\
\hline \multicolumn{2}{|l|}{ Method of administration, $n(\%)$} \\
\hline Metered dose inhaler (MDI) & $65(5.0)$ \\
\hline Dry powder inhaler (DPI) & $49(43.0)$ \\
\hline \multicolumn{2}{|l|}{ Oral anti-inflammatory drugs, $n(\%)$} \\
\hline Antileukotriene & $15(13.2)$ \\
\hline Antihistamine & $63(55.3)$ \\
\hline Intermittent use of short-acting $\beta_{2}$-agonists, $n$ (\%) & $30(26.3)$ \\
\hline
\end{tabular}

The study group consisted of patients receiving inhaled anti-asthmatic drugs for an average period of $58 \pm 42.83$ months. In $102 / 89.5 \%$ patients, a mild type of asthma was diagnosed. Most of the patients (92/80.7\%) received ICS flixotide (fluticasone propionate - FP). ICS as a monotherapy was undertaken by $86.8 \%$ of patients, and $13.2 \%$ received combined therapy with longacting $\beta_{2}$-agonists. Age at asthma diagnosis and duration and type of anti-asthmatic therapy in the study group are presented in Table 2.

Saliva tests using the GC buffer test showed no statistically significant differences between the groups in terms of parameters of resting saliva $\mathrm{pH}(p=0.9703)$, hydration $(p=0.4026)$, or quantity of saliva $(p=0.2231)$ (Table 3$)$. In the study group, sticky saliva $(p=0.0040)$ and very low buffering capacity $(p=0.0001)$ were observed significantly more often than in the control group (Table 3). Statistical analysis of average resting saliva $\mathrm{pH}$, buffering capacities, and saliva quantity showed significant differences between the groups in terms of the two latter parameters $(p=0.0002$ and $p=0.0064$, respectively) (Table 4).

Statistical analysis indicated significant differences between combined therapy and independent ICS ther-

TABLE 3. Saliva properties assessed with GC buffer test

\begin{tabular}{|c|c|c|c|c|c|c|}
\hline \multirow[t]{2}{*}{ Parameter/Assessment } & \multicolumn{2}{|c|}{ Study group } & \multicolumn{2}{|c|}{ Control group } & \multirow[t]{2}{*}{$p$-fraction } & \multirow[t]{2}{*}{$p$-value } \\
\hline & $n$ & $\%$ & $n$ & $\%$ & & \\
\hline \multicolumn{7}{|l|}{ Resting saliva pH } \\
\hline Acidic & 18 & 15.79 & 15 & 15.96 & & \multirow[t]{3}{*}{0.9703} \\
\hline Moderately acidic & 93 & 81.58 & 76 & 80.85 & & \\
\hline Normal & 3 & 2.63 & 3 & 3.19 & & \\
\hline Average value $\pm S D$ & \multicolumn{2}{|c|}{$6.19 \pm 0.613$} & \multicolumn{2}{|c|}{$6.28 \pm 0.65$} & & 0.1621 \\
\hline \multicolumn{7}{|l|}{ Hydration } \\
\hline Low & 88 & 77.19 & 77 & 81.91 & & \multirow[t]{2}{*}{0.4026} \\
\hline Normal/high & 26 & 22.81 & 17 & 18.09 & & \\
\hline \multicolumn{7}{|l|}{ Buffering capacity } \\
\hline Very low & 52 & 45.61 & 19 & 20.21 & $0.0001^{*}$ & \multirow[t]{3}{*}{$0.0005^{*}$} \\
\hline Low & 49 & 42.98 & 62 & 65.96 & $0.0009^{*}$ & \\
\hline Normal & 13 & 11.40 & 13 & 13.83 & 0.6652 & \\
\hline Average value $\pm S D$ & \multicolumn{2}{|c|}{$5.58 \pm 1.89$} & \multicolumn{2}{|c|}{$6.57 \pm 1.94$} & & $0.0002^{*}$ \\
\hline \multicolumn{7}{|l|}{ Quantity of saliva } \\
\hline Very low & 34 & 36.56 & 19 & 24.36 & & \multirow[t]{3}{*}{0.2231} \\
\hline Low & 45 & 48.39 & 46 & 58.97 & & \\
\hline Normal & 14 & 15.05 & 13 & 16.67 & & \\
\hline Average value $\pm S D$ & \multicolumn{2}{|c|}{$4.10 \pm 1.86$} & \multicolumn{2}{|c|}{$4.77 \pm 1.70$} & & $0.0064^{*}$ \\
\hline \multicolumn{7}{|l|}{ Viscosity } \\
\hline Watery, clear saliva & 56 & 49.12 & 61 & 64.89 & $0.0225^{*}$ & \multirow[t]{3}{*}{$0.0094^{*}$} \\
\hline Frothy, bubbly saliva & 33 & 28.95 & 26 & 27.66 & 0.8978 & \\
\hline Sticky, frothy saliva & 25 & 21.93 & 7 & 7.45 & $0.0040^{*}$ & \\
\hline
\end{tabular}


TABLE 4. Average values and frequencies of saliva properties in the study group

\begin{tabular}{|c|c|c|c|c|c|c|c|c|c|c|c|}
\hline \multirow[t]{2}{*}{ Parameter } & \multirow[t]{2}{*}{$n$} & \multicolumn{2}{|c|}{ Resting saliva pH } & \multicolumn{2}{|c|}{ Buffering capacity } & \multicolumn{2}{|c|}{ Quantity of saliva } & \multicolumn{2}{|c|}{ Low hydration } & \multicolumn{2}{|c|}{ Sticky saliva } \\
\hline & & $\begin{array}{c}\text { Average } \\
\pm \text { SD }\end{array}$ & $p$-value & $\begin{array}{l}\text { Average } \\
\pm \text { SD }\end{array}$ & $p$-value & $\begin{array}{l}\text { Average } \\
\pm \text { SD }\end{array}$ & $p$-value & $n(\%)$ & $p$-value & $n(\%)$ & $p$-value \\
\hline ICSs therapy & 99 & $6.19 \pm 0.61$ & \multirow[t]{2}{*}{0.9632} & $5.65 \pm 1.91$ & \multirow[t]{2}{*}{0.5434} & $4.10 \pm 1.96$ & \multirow[t]{2}{*}{0.4709} & $18(18.2)$ & \multirow[t]{2}{*}{$0.0025^{*}$} & $18(18.8)$ & \multirow[t]{2}{*}{$0.0129 *$} \\
\hline $\begin{array}{l}\text { Combined therapy } \\
\text { (ICS }+\beta \text {-agonists) }\end{array}$ & 15 & $6.16 \pm 0.647$ & & $5.13 \pm 1.73$ & & $4.13 \pm 1.03$ & & $8(53.3)$ & & $7(46.7)$ & \\
\hline \multicolumn{12}{|c|}{ Method of administration } \\
\hline MDI & 65 & $6.26 \pm 0.58$ & \multirow[t]{2}{*}{0.3362} & $5.71 \pm 2.04$ & \multirow[t]{2}{*}{0.6409} & $4.50 \pm 1.91$ & \multirow[t]{2}{*}{$0.0275^{*}$} & $11(16.9)$ & \multirow[t]{2}{*}{$0.0846^{*}$} & $10(15.4)$ & \multirow[t]{2}{*}{0.0518} \\
\hline DPI & 49 & $6.09 \pm 0.64$ & & $5.41 \pm 1.67$ & & $3.81 \pm 1.77$ & & $15(30.6)$ & & $15(30.6)$ & \\
\hline
\end{tabular}

TABLE 5. Correlations between anti-asthmatic therapy and salivary properties

\begin{tabular}{|c|c|c|c|c|c|c|c|}
\hline Average numbers & ICS therapy & $\begin{array}{c}\text { Combined therapy } \\
\text { (ICS + long-acting } \\
\beta_{2} \text {-agonists) }\end{array}$ & ICS dose & $\begin{array}{c}\text { Number } \\
\text { of administrations } \\
\text { per day }\end{array}$ & Using DPIs & $\begin{array}{c}\text { Duration } \\
\text { of ICS } \\
\text { therapy }\end{array}$ & $\begin{array}{c}\text { Duration } \\
\text { of combined } \\
\text { therapy }\end{array}$ \\
\hline \multicolumn{8}{|l|}{ Buffer test GC } \\
\hline Resting saliva pH & 0.0788 & -0.0052 & -0.1673 & 0.1396 & 0.1005 & -0.0853 & -0.12254 \\
\hline Hydration & -0.1271 & $-0.2832^{*}$ & -0.0311 & -0.0385 & 0.1615 & $-0.2818^{*}$ & -0.2796 \\
\hline Buffering capacity & -0.0357 & -0.0589 & 0.0143 & -0.0409 & 0.0452 & -0.0086 & 0.2199 \\
\hline Quantity of saliva & -0.0186 & -0.0689 & $-0.1981^{*}$ & -0.1106 & $-0.2099^{*}$ & $-0.2199^{*}$ & 0.4994 \\
\hline Viscosity & 0.0497 & -0.1825 & 0.1125 & -0.0331 & $0.2303^{*}$ & 0.0823 & -0.1627 \\
\hline
\end{tabular}

apy regarding hydration of lip mucosa and consistency of saliva. The results show a greater frequency of low hydration and sticky saliva in patients on a combined therapy than in those on ICS monotherapy ( $p=0.0025$ and $p=0.0129$, respectively) (Table 4 ). Moreover, patients using DPIs were characterized by significantly lesser quantities of saliva than patients using MDIs ( $p=0.0275)$ (Table 4). A similar relationship was found in terms of hydration of lip mucosa and consistency of saliva, with the results being close to statistical significance (Table 4).

Spearman's correlation rank revealed no significant relationships between ICS therapy and saliva properties. According to statistical analysis, the use of combined therapy significantly reduced hydration of the mucosa. Prolonged ICS therapy had a similar effect on this property. Furthermore, Spearman's correlation showed a weak but significant negative relationship between the average quantity of saliva and ICS dose, duration of monotherapy, and use of DPIs. Also, the use of DPIs significantly increased saliva viscosity (Table 5).

\section{DISCUSSION}

Even though, the published literature has been indicating oral health problems in asthmatic patients for quite some time, no clear consensus was made among researchers regarding the influence of type of medication, duration of therapy, or frequency and method of administration. The current study showed that patients with asthma on inhaled therapy demonstrated significantly lower buffering capacity, reduced average quantities, and higher viscosity of saliva compared to healthy patients. A similar observation in terms of buffering capacity was made by Mazzoleni et al. [10], who recorded $43 \%$ of asthmatic patients with low buffer capacity compared to none from control group; in fact, the majority of healthy patients $(60 \%)$ exhibited high buffer capacities of saliva $(p>0.05)$. These observations are comparable with the results of the present study, where nearly $45.6 \%$ of asthmatics were characterized by "very low" buffering capacities compared to the control group (20.2\%). Also, average buffering capacities were significantly lower in the study group $(5.58 \pm 1.89)$ than in controls $(6.57 \pm 1.94)(p=0.0002)$. Bairappan et al. [11], in a study on 50 asthmatics and 50 non-asthmatics, found a significant reduction in mean buffering capacities between the two groups $(p=0.019)$. Contradictory results were obtained by Ersin et al. [13], Alaki et al. [14], and Al-Dlaigan et al. [15], who found no differences in buffering capacities between investigated groups. Moreover, Ersin et al. and Alaki et al. investigated changes in salivary properties in connection with inhaled therapy in asthmatic patients. 
Neither team found any correlation between type and duration of therapy, frequency and method of daily administration, and time of drug inhalation. On the other hand, Bairappan et al. [11] observed a moderate negative correlation between buffering capacity and severity of asthma $(r=-0.84)$, use of combination therapy $(r=-0.515)$, and duration of inhaled therapy $(r=-0.397)$. Alteration in salivary flow, consistency, and buffering capacity may be due to the impact of $\beta_{2}$-agonists, which, according to some observers, affect salivary glands, resulting in diminished production of saliva [17]. This assumption can be confirmed by the findings of the present study, in which, a negative correlation was observed $(r=-0.2832)$ between the use of $\beta_{2}$-agonists and hydration, demonstrating a negative effect of this type of therapy on the salivary gland of lower lip mucosa. However, the present results indicated no correlation between buffering capacity and inhaled anti-asthmatic treatment.

Another frequently described problem in patients with inhaled therapy is xerostomia and diminished saliva flow. In the present study, we observed a reduction in average quantity of saliva in the investigated group compared to the control group $(p=0.0064)$. This result is consistent with the study by Ersin et al. [13]. What is more, reduced saliva flow in the asthmatic group was considered the only significant bivariate variable in the development of caries. However, Alaki et al. [14] observed no differences between studied groups in terms of saliva production. They recorded a reduction in saliva flow along with an increased severity of asthma, related to medications used by patient. A similar relationship was observed by Arafa et al. [18, 19] in two studies assessing the impact of inhaled therapy on the oral health of asthmatic patients. Moreover, apart from the severity of asthma, Bairappan et al. [11] found a significant negative relationship between saliva flow on one hand, and combination therapy $(r=-0.71)$ and duration of therapy $(r=-0.531)$ on the other. Their results are consistent with observations of the current study, as we found a negative correlation between saliva quantity and ICS dose, duration of ICS therapy, and usage of DPIs. However, neither Santos et al. [20] nor Al-Dlaigan et al. [15] noted any differences in saliva flow between asthmatics and healthy patients. The latter team explained this result in terms of difficulties in collecting saliva in smaller patients. However, they found that patients on combined therapy were characterized by reduced saliva flow rate compared to patients using antihistamine or ICS therapy only $(p=0.04)$. They explained that patients with more severe types of asthma used ICS therapy combined with $\beta_{2}$-agonists, which affected their stimulation of saliva. Such effect was also observed in a study by Sag et al. [12] on 28 patients with diagnosed moderate persistent asthma, to whom, a combination treatment with a long-acting $\beta_{2}$-agonist (50 mg salmeterol and $100 \mathrm{mg}$ FP) was administered. Saliva flow was measured before and after one month of treatment. The authors observed a statistically significant difference between the two measurements $(p=0.0015)$. However, they assumed that the reduction in saliva production was a result of the disease itself, as the treatment period was quite short for such a drastic effect in patients with moderate asthma. Wogelius et al. [21] also found an association of $\beta_{2}$-agonists with oral health, especially development of caries. In the present study, no significant relationship was observed between saliva flow and the use of $\beta_{2}$-agonists. These differences in outcomes could be due to the small group of patients on combined therapy in the present study, which involved mostly patients with mild asthma compared to only some with moderate type of asthma. Therefore, lower dosage of inhaled medications may not influence oral health as strongly as initially presumed.

The final examined property of saliva was its resting $\mathrm{pH}$. The results of the current study showed no differences between the group of asthmatics and healthy patients. Nor did the authors observe any correlations between $\mathrm{pH}$ value and inhaled therapy. Similar results were obtained by Santos et al. [20] and Al-Dlaigan et al. [15] studies, where no significant differences were found between two investigated groups. However, Khalifa et al. [22] observed a significant reduction in $\mathrm{pH}$ value in asthmatic patients compared to control group. This result is consistent with those of Ersin et al. [13] and Konde et al. [23], who not only found a significant decrease in salivary $\mathrm{pH}$ in asthmatics, but also observed a significant effect of inhaled therapy on this value. Ersin et al. found a negative correlation between a duration of medication and $\mathrm{pH}$ value $(p=0.017, r=-0.28)$, whereas Konde et al. observed a significant relationship between combination therapy and reduced $\mathrm{pH}$ compared to values of patients using salbutamol or ICS independently. Additionally, Arafa et al. [18,19] presented a relationship between severity of asthma and $\mathrm{pH}$ value of resting saliva, which might also be related to the different types of medications used. Similarly, Bairappan et al. [11] showed a negative correlation between salivary $\mathrm{pH}$ and severity of asthma, duration of inhaled therapy, and usage of combined therapy. Kargul et al. [17] presented the effect of $\beta_{2}$-agonists on the flow and composition of saliva, observing that $\mathrm{pH}$ value decreased significantly 30 minutes after drug application. On the other hand, Tootla et al. [24] observed no decrease in $\mathrm{pH}$ below a critical value of 5.5, which leads to demineralization. However, they learned that DPIs based on lactose as a flavor enhancer caused significantly lower $\mathrm{pH}$ values, which may be an important factor leading to the development of cariogenic bacteria and enamel demineralization. This observation is consistent with the result of the current study, as the authors observed a negative correlation between the use of DPIs and quantity of saliva $(r=-0.209891)$. Another finding was a positive relationship between DPIs treatment and saliva viscosity, as confirmed by Shashikiran et al. [25]. 


\section{CONCLUSIONS}

The present study shows that inhaled anti-asthmatic medications provide a considerable effect on salivary properties, especially buffering capacity, quantity, and viscosity. Many factors may affect saliva: not only the type of medication, but also its dosage, duration of the therapy, number of applications, and method of administration. As a result, asthmatics are considered to be at high-risk of developing caries, periodontitis, and sudden changes in their bacterial and fungal oral environments. Therefore, it is important to educate patients, parents, and medical specialists regarding the importance of dental care and prophylaxis, in order to improve the quality of life of these patients.

\section{CONFLICT OF INTEREST}

The authors declare no potential conflicts of interest with respect to the research, authorship, and/or publication of this article.

\section{References}

1. The Global Asthma Report 2018. Auckland, New Zealand: Global Asthma Network; 2018.

2. Dharmage SC, Perret JL, Custovic A. Epidemiology of asthma in children and adults. Front Pediatr 2019; 7: 246

3. Robinson CL, Baumann LM, Romero K, et al. Effect of urbanization on asthma, allergy and airways inflammation in a developing country setting. Thorax 2011; 66: 1051-1057.

4. Chavasse R, Scott S. The differences in acute management of asthma in adults and children. Front Pediatr 2019; 7: 64.

5. Agostini BA, Collares KF, Costa FDS, Correa MB, Demarco FF. The role of asthma in caries occurrence - meta-analysis and metaregression. J Asthma 2019; 56: 841-852.

6. Carhuamaca-Salvador M, Bustos de la Cruz J, Chávez-Rimache L, Chumpitaz-Cerrate V. Risk of dental caries in pediatric asthmatic patients undergoing treatment with salbutamol and budesonide inhalation therapy, Peru. Rev Fac Cien Med Univ Nac Cordoba 2019; 76: 222-226.

7. Chandan JS, Randhawa RS, Thomas T. Oral health: asthma and oral candidiasis. Br Dent J 2017; 223: 621.

8. Rukshana F, Rekha S, Praveen SJ, Laxminarayan S, Imran PM. Evaluation of salivary parameters and oral health status among asthmatic and nonasthmatic adult patients visiting a tertiary care hospital. Cureus 2019; 11: e5957.

9. Strużycka I, Rusyan E, Bogusławska-Kapała A. Epidemiological study of prevalence and risk factors for dental erosions among Polish young adults. Pol Merkur Lekarski 2016; 40: 308-313 [In Polish].

10. Mazzoleni S, Stellini E, Cavaleri E, Volponi AA, Ferro R, Colombani SF. Dental caries in children with asthma undergoing treatment with short-acting beta ${ }_{2}$-agonists. Eur J Paediatr Dent 2008; 9: 132-138.

11. Bairappan S, Puranik MP, Sowmya KR. Impact of asthma and its medication on salivary characteristics and oral health in adolescents: a cross sectional comparative study. Spec Care Dentist 2020; 40: 227-237.

12. Sag C, Feyza OO, Gokhan A, Anlar FY. The effects of combination treatment with a long-acting beta2-agonistand a corticosteroid on salivary flow rate, secretory immunoglobulin $\mathrm{A}$, and oral health in children and adolescents with moderate asthma: a 1-month, single blind study. Clin Ther 2007; 29: 2236-2242.
13. Ersin NK, Gülen F, Eronat N, et al. Oral and dental manifestations of young asthmatics related to medication, severity and duration of condition. Pediatr Int 2006; 48: 549-554.

14. Alaki SM, Ashiry EA, Bakry NS, Baghlaf KK, Bagher SM. The effects of asthma and asthma medication on dental caries and salivary characteristics in children. Oral Health Prev Dent 2013; 11 113-120.

15. Al-Dlaigan YH, Shaw L, Smith AJ. Is there a relationship between asthma and dental erosion? A case control study. Int J Paediatr Dent 2002; 12: 189-200.

16. Global Initiative for Asthma. Global Strategy for Asthma Management and Prevention, 2020. Available from: www.ginasthma.org.

17. Kargul B, Tanboga I, Ergeneli S, Karakoc F, Dagli E. Inhaler medicament effects on saliva and plaque $\mathrm{pH}$ in asthmatic children. J Clin Pediatr Dent 1998; 22: 137-140.

18. Arafa A, Aldahlawi S, Hussien A. Impact of secretory immunoglobulin A level on dental caries experience in asthmatic children. Int J Clin Pediatr Dent 2019; 12: 414-418.

19. Arafa A, Aldahlawi S, Fathi A. Assessment of the oral health status of asthmatic children. Eur J Dent 2017; 11: 357-363.

20. Santos NC, Jamelli S, Costa L, et al. Assessing caries, dental plaque and salivary flow in asthmatic adolescents using inhaled corticosteroids. Allergol Immunopathol (Madr) 2012; 40: 220-224.

21. Wogelius P, Poulsen S, Sørensen HT. Use of asthma-drugs and risk of dental caries among 5 to 7 -year-old Danish children: a cohort study. Community Dent Health 2004; 21: 207-211.

22. Khalifa MAAA., Abouelkheir HM, Khodiar SEF, Mohamed GAM. Salivary composition and dental caries among children-controlled asthmatics. Egypt J Chest Dis Tuberc 2014; 63: 777-788.

23. Konde S, Agarwal M, Chaurasia R. Effects of inhalational antiasthmatic medication on oral health between 7 and 14 years of age. Indian J Allergy Asthma Immunol 2018; 32: 70-73.

24. Tootla R, Toumba KJ, Duggal MS. An evaluation of the acidogenic potential of asthma inhalers. Arch Oral Biol 2004; 49: 275-283.

25. Shashikiran ND, Reddy VVS, Raju PK. Effect of antiasthmatic medication on dental disease: dental caries and periodontal disease. J Indian Soc Pedod Prev Dent 2007; 25: 65-68. 